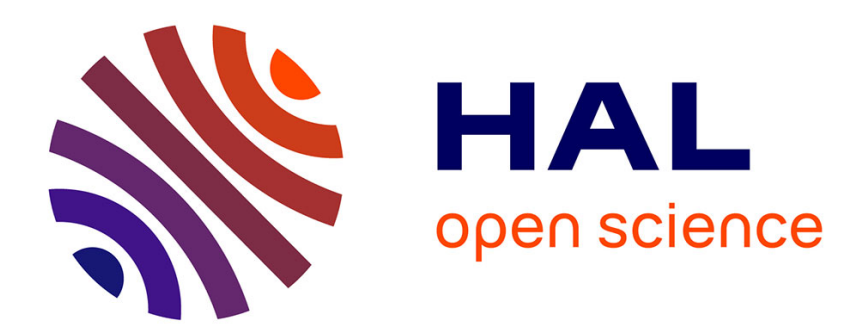

\title{
Subsidy Policy for Innovation: A way to reach objectives of both higher growth and equity?
}

Benjamin Montmartin

\section{To cite this version:}

Benjamin Montmartin. Subsidy Policy for Innovation: A way to reach objectives of both higher growth and equity?. 2010. halshs-00537867

\section{HAL Id: halshs-00537867 \\ https://shs.hal.science/halshs-00537867}

Submitted on 19 Nov 2010

HAL is a multi-disciplinary open access archive for the deposit and dissemination of scientific research documents, whether they are published or not. The documents may come from teaching and research institutions in France or abroad, or from public or private research centers.
L'archive ouverte pluridisciplinaire HAL, est destinée au dépôt et à la diffusion de documents scientifiques de niveau recherche, publiés ou non, émanant des établissements d'enseignement et de recherche français ou étrangers, des laboratoires publics ou privés. 
Subsidy Policy for Innovation: A way to reach objectives of both higher growth and equity?

Benjamin Montmartin

Novembre 2010 


\section{GATE Groupe d'Analyse et de Théorie Économique Lyon-St Étienne}

93, chemin des Mouilles 69130 Ecully - France

Tel. +33 (0)4 72866060

Fax $+33(0) 472866090$

6, rue Basse des Rives 42023 Saint-Etienne cedex 02 - France

Tel. +33 (0)4 77421960

Fax. $+33(0) 477421950$

Messagerie électronique / Email : gate@gate.cnrs.fr

Téléchargement / Download : http://www.gate.cnrs.fr - Publications / Working Papers 


\title{
Subsidy Policy for Innovation: A way to reach objectives of both higher growth and equity?
}

\author{
Benjamin Montmartin *
}

November 18, 2010

\begin{abstract}
Since the Lisbon Agenda (2000), the European Union policies are increasingly oriented towards innovation as attested to by the deep change of the new Regional Policy. This paper proposes an analysis of an innovation subsidy policy in an agglomeration and growth model à la Martin and Ottaviano (1999). In this two-regions model, we assume that the policy is implemented by a central authority that taxes the profit of industrial firms to subsidy employment in innovative activities. We show that the positive effects on growth and equity of such a policy, as highlighted by Martin (1999), hold in the case where the policy is not geographically differentiated. In the case where the government however grants larger subsidies to the poorer region in order to reduce the concentration of the innovative sector, we show that the policy can be inefficient if it is not of sufficient magnitude.
\end{abstract}

JEL classification: $\mathrm{F} 43, \mathrm{H} 50, \mathrm{O} 30, \mathrm{R} 12$

Keywords: economic geography, endogenous growth, public policy, subsidies, Regional Policy

\footnotetext{
*Université de Lyon, Lyon, F-69003, France; Université Jean Monnet, Saint-Etienne, F-42000, France; CNRS, GATE Lyon St Etienne, Saint-Etienne, F-42000, France, e-mail: benjamin.montmartin@univ-st-etienne.fr
} 


\section{Introduction}

Since the Lisbon Agenda (2000), a growing number of European policies aim to support and strengthen the European dynamics of innovation. Although the objectives of this treaty have not been reached - 3\% of the European Union GDP had to be devoted to R\&D in 2010 (against only 1,9\% of GDP in 2008) - it appears that an increasing proportion of the EU budget is devoted to supporting R\&D projects. Thus, the annual budget of $7^{\text {th }}$ Framework Program of Research and Development (2007-2013) increased by more than 60\% when compared to the $6^{\text {th }}$. Another example which probably represents the most important change, concerns the European Regional Policy which was created to reduce regional disparities and support the development of lagging regions. Indeed, in previous programs, funds were mainly used to finance transport infrastructures ${ }^{1}$ in poorer regions and richer regions were not eligible for this program. The new Regional Policy (2007-2013) has deeply changed the strategy allocating for funds according to the objectives of the Lisbon treaty. For instance, whereas only 10,5 billion euros were used to finance innovation projects in the previous program, at least 183 billion euros will be used for this purpose within the next one. Moreover, in this new program all European regions can obtain funds for innovative projects (even though a part of the funds is still reserved for poor regions). In our point of view, this reflects a deep change in the European authorities vision of the best way to reach the objectives of both a higher growth and a reduction of disparities between regions, i.e, by helping all regions to develop through innovation in order to find their place in an economic system based up on knowledge.

Is this shift of European public policies in favor of innovation able to better meet the objectives of growth and equity?

Empirical works of Barro and Sala-i-Martin (1996), Quah (1996) and more recently Heraud et al. (2004) have shown that the convergence of European countries has been accompanied by an increasing phenomenon of regional inequalities. Walz (1996) and later Martin and Ottaviano (1999) give a theoretical explanation of this phenomenon showing that in the presence of localized knowledge externalities, the aggregate growth rate is partly driven by the agglomeration of economic activities. This relation, in a context of increasing economic integration which reduces the attractivity of poorer regions (by removing the final barriers protecting them from foreign competition), increases incentives to agglomerate. Therefore, the European context would explain the empirical observation mentioned above. A naturally related question aims to understand

\footnotetext{
${ }^{1}$ See Becker and Fuest (2010) for more details.
} 
whether or not some public policies would be able to reduce regional inequalities without reducing growth. Martin (1999), Baldwin et al. (2003) or Riou (2003) are among the few to have dealt with this issue. Their papers analyze the impact of different public policies upon growth and regional inequalities. Their results suggest that most public policies implemented in previous European Regional Policy, such as direct transfer or the development of transport infrastructures, would lead to a trade off between growth and equity. They also suggest that a public policy reducing the cost of innovation or facilitating the transfer of knowledge would be able to reach both objectives of the European Commission. This theoretical result is most important in the sense that it implies that public policy could limit the trend of increasing regional inequalities while strengthening economic growth. The strategic shift of the Regional Policy therefore appears to beheading in the right direction.

Nevertheless, a direct application of the teachings gained from these models in terms of public policy could be misleading insofar as in these contributions, the public sector is not modeled and the analysis of public policy does not highlight all of its effects. The aim of this paper is to improve the theoretical understanding of the effects on growth and equity of a public policy oriented towards innovative activities, by introducing a public sector within the model proposed by Martin and Ottavino (1999). The advantage of this framework is that it achieves a synthesis between the new economic geography and the new growth theory. All contributions in this field of literature use a growth process à la Romer (1990) and Grossman and Helpman (1991), i.e, the growth consists of the permanent increase in the number of goods and increases with the amount of resources devoted to the research sector. There exists however, some differences in the "location" framework used and we can break these contributions down into two categories, as reported in table 1 at the end of the introduction. The first class of models includes cumulative causation mechanisms related to the migration or vertical linkages whereas the second one with Footloose Capital framework (see Baldwin et al. (2003), ch.3) excludes such mechanisms. Indeed, the FC model cuts both the demand-linked and cost-linked circular causality which are present in CP models by assuming that the mobile factor repatriates all of its earnings to its country of origin. Consequently, the first class of agglomeration and growth models (with a CP or VL framework) focused mainly upon the study of the stability of symmetric or Core-Periphery configurations in a context of economic integration. Some papers however using an FC framework are more oriented towards studying the impacts of different public policies. Indeed, within such a framework, the location equilibrium is always stable and economists do not need to address issues of stability. For this reason and for the sake of simplicity we will use an agglomeration and growth model with a Footloose Capital framework.

Using the framework of Martin and Ottaviano (1999), we add a public sector which taxes industrial firms (or a part of GDP) to subsidize employment in inno- 
vative activities. We assume that the tax rate is the same in both regions ${ }^{2}$ but we do not restrict the geographical allocation of subsidies allowing government to try to influence the geography of innovative activities ${ }^{3}$. To our mind, this is an important point to investigate because today, for many policy makers, the relevant question is more to know whether or not innovation policies have to limit the concentration of innovative activities than discuss the benefit of such policies. To be more realistic, we also assume, as do Baldwin et al. (2001) that knowledge externalities are not global or local but partially localized ${ }^{4}$.

Our first result concerns the relation between growth and geography of economic activities. In previous contributions, the whole innovative sector has been localized within the richer region in order to benefit from higher knowledge externalities so that only the location of industrial activities affects the growth rate. In our case, the government may change the geography of innovation so that the equilibrium location of innovative firms will have an impact upon growth. We show that the concentration of industrial firms within a region supports growth only if the majority of innovative firms are located in this region. This result gives theoretical proof that the growth is fueled by the concentration of all economic activities from design to production. We also show that for the particular case where researchers are dispersed between regions, then the geography of economic activities has no impact upon the growth rate.

Concerning the effects of the public subsidy for equity and growth, our results suggest that, if the subsidy policy is undifferentiated across regions, then the equilibrium outcome is more efficient and reduce regional inequalities. If however, the government also wants to change the geography of innovation and proposes a different level of subsidy then, it is forced to fix its tax rate above a certain threshold level in order to reduce regional inequalities and increase the growth rate (compared to the case where no public policy is implemented). Below this threshold level, the differentiated subsidy policy is inefficient and increases inequalities. It should also be noted that the more innovative firms are dispersed the more the threshold tax rate increases and the less the public policy is efficient. Two reasons explain this, the first being that a portion of public funds is used to compensate for the attractivity gap between regions instead of being used to reduce the cost of innovation. The second is that the average productivity of $R \& D$ is lower when innovative firms are more dispersed (because of localized spillovers).

We present our framework in the next section. Section 3 presents our assumptions concerning the innovation process and from those we derive the equilibrium

\footnotetext{
${ }^{2}$ Note that this hypothesis is not as restrictive concerning European policy because more than $70 \%$ of EU budget comes from a uniform tax rate on GDP.

${ }^{3}$ Regional Policy is clearly oriented towards poor regions (Nearly $80 \%$.)

${ }^{4}$ See Riou (2003) for details about this hypothesis.
} 
growth rate which depends upon the geography of industrial and innovative firms. Section 4 defines the income inequalities and the steady state. Section 5 analyzes the effects of the subsidy policy and how the geography of innovative activities affects its efficiency.

\begin{tabular}{|c|c|}
\hline $\begin{array}{c}\text { Core Periphery and } \\
\text { Vertical linkage }\end{array}$ & Footloose Capital \\
\hline Englmann and Walz (1995) & Martin and Ottaviano(1999) \\
Walz (1996, 1999) & Martin (1999) \\
Baldwin and Forslid (2000b) & Baldwin and Forslid (2000a) \\
Martin and Ottaviano (2001) & Baldwin, Martin and Ottaviano (2001) \\
Fujita and Thisse (2002) & Riou (2003) \\
Minniti and Parello (2010) & Baldwin and Martin (2004) \\
\hline
\end{tabular}

Table 1: Location structure in "agglomeration and growth" models

\section{The general framework}

\subsection{A brief introduction}

The general framework is similar to that of Martin and Ottaviano (1999). The world consists of two regions $i$ and $j$. There are three sectors (traditional $(\mathrm{T})$, manufacturing $(\mathrm{M})$ and innovation $(\mathrm{I})$ ) and two factors of production (knowledge capital $(\mathrm{K})$ and labor $(\mathrm{L})$ ). T-sector is perfectly competitive and produces an homogeneous good. In this sector, firms use one unit of labor to produce one unit of good and trade is costless. Firms in the M-sector face Dixit-Stiglitz monopolistic competition and increasing returns. Each differentiated variety is produced by a single M-firm using $\beta$ units of labor and one unit of knowledge capital. Trade in M-varieties is subject to Iceberg cost so $\tau>1$ units must be shipped to sell one unit abroad. I-sector is perfectly competitive and firms produce one unit of $K$ with $a_{I}$ units of $L$. I-Firms sell blueprints of variety to $\mathrm{M}$-sector firms with an infinite-lived patent which gives $\mathrm{M}$-firms a perpetual monopoly rent. We add to this framework a central government who will use the fiscal tool to implement a subsidy policy for innovative firms. We suppose that the government gives an employment subsidy for R\&D activities which is funded by a tax on the operating profit of $\mathrm{M}$-firms ${ }^{5}$.

In each region, labor endowment is fixed and equal to $L$. Contrary to knowledge capital, which is supposed to be perfectly mobile, labor is geographically

\footnotetext{
${ }^{5}$ We will see later that a proportional tax on the operating profit of $\mathrm{M}$-firms is equivalent to a tax on GDP to within a constant.
} 
immobile but sectorially mobile. It should be noted that as long as $\mathrm{T}$-sector is active in both regions and using the homogeneous good as numeraire, the wage rate and the price of the homogeneous good are equal to one. We suppose this condition to always be satisfied ${ }^{6}$.

Finally the two regions are identical except for their initial level of non-labor wealth. We suppose that the region $i$ is initially richer than region $j$. Specifically, we assume that consumers in region $i$ own more units of knowledge capital than in region $j$ such that :

$$
K_{i}(0)>K_{j}(0)
$$

where $K_{i}$ and $K_{j}$ represent the number of M-firms owned by regions $i$ and $j$. The free capital mobility hypothesis ensures a symmetric yield of shares and therefore the incentives to accumulate capital are the same in both regions. This implies that the share of knowledge capital owned by each region is stable over time and given by the initial distribution $\left(K_{i}(0)\right.$ and $\left.K_{j}(0)\right)$.

\subsection{Optimal consumption and production}

Let $N_{w}$ be the number of differentiated varieties available in the economy. Consumer preferences are given by a Cobb-Douglas utility function and inter temporally CES function with unit elasticity of intertemporal substitution:

$$
\int_{0}^{\infty} \ln \left[D(t)^{\alpha} Y(t)^{1-\alpha}\right] e^{-\rho t} d t
$$

where $Y$ is the consumption of the homogeneous good, $\rho \in[0 ; 1]$ is the time preference and $\alpha \in[0 ; 1]$ represents the share of expenditure devoted to the consumption of differentiated goods. Demand for differentiated goods in region $i$ is represented by a CES function à la Dixit-Stiglitz (1977):

$$
D_{i}(t)=\left[\int_{0}^{N_{i}} D_{i}^{i}(t)^{\frac{\sigma-1}{\sigma}} d i+\int_{0}^{N_{j}} D_{i}^{j}(t)^{\frac{\sigma-1}{\sigma}} d i\right]^{\frac{\sigma}{\sigma-1}}
$$

where $N_{i}$ and $N_{j}$ are the number of M-firms located in regions $i$ and $j$ such that $N_{w}=N_{i}+N_{j}$ and $\sigma$ represents the elasticity of substitution between varieties as well as the price elasticity of demand for each variety. The expenditures of a representative consumer located in region $i$ are given by:

$$
E_{i}(t)=\left[\int_{0}^{N_{i}} D_{i}^{i}(t) P_{i}^{i} d i+\int_{0}^{N_{j}} D_{i}^{j}(t) P_{i}^{j} d i+P_{Y} Y_{i}\right]
$$

\footnotetext{
${ }^{6}$ To find this condition, we have to find the condition under which all M-firms are located in region $i$ and region $j$ cannot satisfy the global demand for the homogeneous good. This condition is given by : $(1-\alpha)\left[2 L+\rho\left(1-S_{i}\right)\right]>L$.
} 
$D_{i}^{i}$ and $D_{i}^{j}$ are demands of a consumer located in $i$ for a variety produced in region $i$ and $j . P_{i}^{i}$ and $P_{i}^{j}$ are prices of the $\mathrm{i}$-th variety produced in $i$ and $j$. In what follows we leave implicit the dependence of variables upon time except for initial variables subscripted by 0 .

Consumers solve their maximization problem in two separate steps. Firstly, the consumer maximizes his utility (2) with respect to his budget constraint (4). For a representative consumer located in region $i$, we have:

$$
\begin{gathered}
Y_{i}=(1-\alpha) E_{i} \\
D_{i}^{i}=\frac{\alpha E_{i}\left(P_{i}^{i}\right)^{-\sigma}}{\Delta} \quad D_{i}^{j}=\frac{\alpha E_{i}\left(P_{i}^{j}\right)^{-\sigma}}{\Delta} \\
\Delta=\int_{0}^{N_{i}}\left(P_{i}^{i}\right)^{1-\sigma}+\int_{0}^{N_{j}}\left(P_{i}^{j}\right)^{1-\sigma}
\end{gathered}
$$

Secondly, the representative consumer achieves an intertemporal trade off between consumption and saving. As in Grossman and Helpman (1991, chp.3), saving takes place in the form of a riskless asset that pays an interest rate $r$ or in the form of investment in shares of $\mathrm{M}$-firms on a world stock market ${ }^{7}$. In this market, M-firms finance the unit of knowledge capital which they are required to produce. Thus, the consumer maximizes his utility (2) with respect to his intertemporal budget constraint:

$$
\dot{a}(t)=w(t)+r(t) a(t)-E_{i}(t)
$$

where $a(t)$ is the value of the assets' stock of a representative consumer. By solving the Hamiltonian, we obtain the Euler equation for the evolution of expenditures:

$$
\frac{\dot{E}_{i}}{E_{i}}=r(t)-\rho
$$

The growth rate of individual expenditures in region $i$ is equal to the difference between the interest rate and the rate of time preference. Note that as the consumers' preferences are the same in both regions, the growth rate of expenditures is also the same.

On the supply side, M-firms have the same technology and the tax rate is the same in both regions, so we can write the post-tax operating profit of a firm located in region $i$ as:

$$
\Pi_{i}=\left[\left(P_{i}^{i} L D_{i}^{i}+P_{j}^{i} L D_{j}^{i}\right)-\beta\left(L D_{i}^{i}+\tau L D_{j}^{i}\right)\right](1-T)
$$

\footnotetext{
${ }^{7}$ In this kind of models, firm shares are riskless assets because they will reflect the real value of firms. This is due to the fact that we remove the case of the speculative bubble.
} 
$T$ is the tax rate and note that, as trade is subject to Iceberg cost, M-firms have to produce $\tau L D_{j}^{i}$ to meet foreign demand.

The optimal pricing policy for M-firms located in region $i$ consists of applying a constant margin on marginal cost. By maximizing (8), we obtain:

$$
P_{i}^{i}=\frac{\beta \sigma}{\sigma-1} \quad P_{j}^{i}=\frac{\tau \beta \sigma}{\sigma-1}
$$

As behaviors of firms and consumers are the same in both regions, we can rewrite the operating profit of a firm located in region $i$ as:

$$
\Pi_{i}=\frac{\beta x_{i}}{\sigma-1}(1-T)
$$

$x_{i}=L D_{i}^{i}+\tau L D_{j}^{i}$ is the production of a firm located in region $i$ and we have a symmetric expression for region $j$.

\subsection{Location equilibrium of M-firms}

In a first step, we introduce optimal prices (9) in demand functions (6) to obtain optimal demands of a consumer located in region $i$ :

$$
D_{i}^{i}=\frac{\sigma-1}{\beta \sigma} \frac{\alpha E_{i}}{N_{i}+\phi N_{j}} \quad D_{i}^{j}=\frac{\sigma-1}{\beta \sigma} \frac{\alpha E_{i} \tau^{-\sigma}}{N_{i}+\phi N_{j}}
$$

where $\phi=\tau^{1-\sigma}$ represents the level of trade integration. Following Martin et Rogers (1995) and Martin (1999), $\tau$ is related to the quality of transport infrastructures. A reduction of $\tau$ corresponds to an improvement of transport infrastructures and therefore to an increase of $\phi(d \phi / d \tau<0)$.

Now, we have to define the condition which ensures equilibrium on differentiated goods market. Using expressions (11) and symmetrical expressions for region $j$, we get the level of production in each region:

$$
\begin{aligned}
& x_{i}=\frac{\alpha L(\sigma-1)}{\beta \sigma N_{w}}\left(\frac{E_{i}}{\left[s_{n}+\phi\left(1-s_{n}\right)\right]}+\frac{\phi E_{j}}{\left[\phi s_{n}+\left(1-s_{n}\right)\right]}\right) \\
& x_{j}=\frac{\alpha L(\sigma-1)}{\beta \sigma N_{w}}\left(\frac{\phi E_{i}}{\left[s_{n}+\phi\left(1-s_{n}\right)\right]}+\frac{E_{j}}{\left[\phi s_{n}+\left(1-s_{n}\right)\right]}\right)
\end{aligned}
$$

where $s_{n}=N_{i} / N_{w}$ is the share of M-firms located in region $i$. With perfect capital mobility, location equilibrium must satisfy the condition of equality of post-tax operating profit. Indeed, for a constant share of manufacturing firms 
$\left(s_{n}\right)$ exists, $\mathrm{M}$-firms must have no incentives to relocate their production, i.e, $\Pi_{i}(1-T)=\Pi_{j}(1-T)$. Using equations (12) and (13), we obtain:

$$
s_{n}=\frac{s_{e}-\phi\left(1-s_{e}\right)}{(1-\phi)}
$$

where $s_{e}=E_{i} / E_{w}$ is the share of expenditures and income held by region $i$ 's consumers. As usual within a New Economic Geography framework, we have the presence of an Home Market Effect. The Home Market Effect refers to the fact that a region with a higher level of expenditures will attract a more than proportional share of M-firms $\left(s_{n}>s_{e}\right)$. The Home Market Effect is given by:

$$
s_{n}-s_{e}=\frac{\phi\left(2 s_{e}-1\right)}{1-\phi}
$$

Note that the higher trade integration is the higher the Home Market Effect and the concentration of $\mathrm{M}$-firms in the richer region are. Finally, we can establish the equilibrium production of $\mathrm{M}$-firms for a given level of expenditures by introducing (14) in (12):

$$
x=\alpha L \frac{\sigma-1}{\beta \sigma} \frac{E_{w}}{N_{w}}
$$

Expression (15) corresponds to the optimal production of all M-firms (regardless of their location). Note that replacing (15) in (10), we can rewrite the operating profit of all M-firms which corresponds to the tax base for the government as:

$$
T B=N_{w} \Pi=\frac{\alpha L E_{w}}{\sigma}
$$

This last expression shows us that a uniform tax on operating profit of M-firms is equivalent to a tax on the GDP to within one constant.

\section{Innovation process, location of R\&D activities and the steady state}

\subsection{Innovation process and knowledge externalities}

In this model, the innovation sector works as for Grossman and Helpman (1991, chap.3). Innovation consists of the increase of the number of available $\mathrm{M}$-varieties and is a constant returns to scale activity for individual firms. It produces however, external increasing returns to scale. In order to produce one unit of knowledge capital, researchers must use $a_{I}$ units of labor and, as in Romer (1990), we suppose that $a_{I}$ follows a learning curve, i.e, the marginal cost of one unit of knowledge capital decreases gradually as the number of M-firms 
increases (the R\&D productivity increases with the number of M-firms). Therefore, knowledge spillovers are transmitted from production to design. Moreover, following Baldwin et al. (2001) and works on geography of innovation, we make the assumption that these knowledge externalities are partially localized. This implies that the production cost of knowledge capital within a region depends negatively on the number of local $\mathrm{M}$-firms and to a lesser extent on the number of $\mathrm{M}$-firms located in the other region ${ }^{8}$.

The central government uses tax income to subsidize I-firms. More specifically, we assume that it gives a subsidy for employment in $R \& D{ }^{9}$. If we assume a uniform tax rate on the operating profit of $\mathrm{M}$-firms in both regions, we do not set constraints on the geographical allocation of subsidies. Thus, the government can offer different levels of subsidies depending on regions in order to change the geography of innovation.

These assumptions can be summarized as follows:

$$
\begin{gathered}
\dot{K}_{w}=\frac{L_{I}^{i}}{a_{I}^{i}}+\frac{L_{I}^{j}}{a_{I}^{j}} \\
a_{I}^{i} \equiv \frac{1}{K_{w} A_{i}} \quad a_{I}^{j} \equiv \frac{1}{K_{w} A_{j}} \\
A_{i}=s_{n}+\lambda\left(1-s_{n}\right) \quad A_{j}=\lambda s_{n}+1-s_{n}
\end{gathered}
$$

where $a_{I}^{i}$ and $a_{I}^{j}$ represent the productivity of R\&D in region $i$ and $j, A_{i}$ and $A_{j}$ represent knowledge externalities for I-firms located in region $i$ and $j, L_{I}^{i}$ and $L_{I}^{j}$ are the quantity of labor employed in $\mathrm{R} \& \mathrm{D}$ in region $i$ and $j$ and $\lambda \in[0,1]$ is the geographical scope of spillovers, i.e, the lower $\lambda$ is the more localized spillovers are. Using (16) and the fact that the wage rate is equal to one, we can write the cost of producing one unit of knowledge capital as:

$$
F_{I}^{i}=\frac{1-S_{i}}{K_{w} A_{i}} \quad F_{I}^{j}=\frac{1-S_{j}}{K_{w} A_{j}}
$$

where $S_{i}$ and $S_{j}$ represent the amount of subsidy per unit of labor in regions $i$ and $j$.

\subsection{Location of innovative firms with a balanced budget}

R\&D activities will locate in the region where the post subsidy innovation cost is the lowest. Note that, without government (as for Martin and Ottaviano,

\footnotetext{
${ }^{8}$ See Riou (2003) for discussions concerning this assumption.

${ }^{9}$ The main justification for this choice is technical as a subsidy on the total cost of innovation would make the model unstable. In addition, note that most R\&D subsidies partly finance the cost of researchers (like the C.I.R program in France or the European Framework Program of Research and Development.)
} 
1999) or if the level of subsidy offered is the same in both regions, all I-firms are located in region $i$. The reason is simply that as the number of $\mathrm{M}$-firms located in region $i$ is higher than in region $j$ at the equilibrium, see (14), the productivity of R\&D is higher in region $i\left(a_{I}^{i}<a_{I}^{j}\right)$. Therefore, if the government wants to change the geography of innovation it has to differentiate the level of subsidy between regions. To have an impact upon the geography of I-firms, the government has to fix (at least) the level of subsidies such as the cost of innovation is the same in both regions. But even in this case, the government cannot be sure that the policy will affect the location of I-firms ${ }^{10}$. This will depend on how the policy is implemented. For instance, we can imagine two different ways of implementing this kind of policy. First case: the government announces a different level of subsidy whatever the I-firm's location choice. In this case, the government cannot be sure that public policy will affect the geography of innovation or that all spatial configuration of I-firms may be obtained. Second case: the government chooses a distribution of $R \& D$ employment between regions in a first step. In a second step, it announces the different level of subsidies and the part of R\&D employment that it will subsidy in for instance the richer region. In this case, a number of the I-firms will move to the poorer region in order to benefit from the subsidy offered in this region. This number will exactly correspond to the part of $R \& D$ employment that the government has chosen to subsidize within one constant ${ }^{11}$.

As the effect of our public policy depends upon its implementation, we will study cases where the policy succeeds or fails to affect the geography of innovation. In either case, the condition that ensures a symmetric cost of innovation $\left(F_{I}^{i}=F_{I}^{j}\right)$ is given by:

$$
S_{j}=1-\frac{A_{j}\left(1-S_{i}\right)}{A_{j}}
$$

In order to express the level of subsidies, we have to find the world labor demand for R\&D activities using expressions (16):

$$
L_{I}=\frac{g}{\theta A_{i}+(1-\theta) A_{j}}
$$

where $L_{I}$ is the world quantity of labor employed in R\&D activities, $g$ the aggregate growth rate and $\theta=L_{I}^{i} / L_{I}$ the share of labor employed in R\&D and located in region $i$. Note that the denominator of (18) can be viewed as the average productivity of R\&D activities.

In this model, we suppose that the government has a balanced budget constraint. The rule of balanced budget for the government is satisfied when the

\footnotetext{
${ }^{10}$ This is due to the fact that I-sector is assumed to be perfectly competitive.

${ }^{11}$ Specifically the part of I-firms located in region $i$ will be equal to : $\frac{\theta A_{i}}{\theta A_{i}+(1-\theta) A_{j}}$.
} 
tax income is equal to the sum of expenditures. The government tax revenue is the sum of taxes collected from the $N_{w} \mathrm{M}$-firms which corresponds to $T$ times the tax base :

$$
R=T \frac{\alpha L E_{w}}{\sigma}
$$

Total government expenditures is simply equal to the labor employed in R\&D multiplied by the amount of the subsidy for each region:

$$
G E=L_{I}\left[\theta S_{i}+(1-\theta) S_{j}\right]
$$

Using equations (17) and (18), we can express the condition satisfying the budget constraint and a symmetric cost of innovation as:

$$
S_{j}=\frac{\theta\left(A_{i}-A_{j}\right)}{\left.\left[\theta A_{i}+(1-\theta) A_{j}\right)\right]}+\frac{\alpha T L E_{w} A_{j}}{g \sigma}
$$

Expression (19) shows us that the higher the spatial concentration of I-firms in region $i$, the higher region $j$ 's subsidy for $\mathrm{R} \& \mathrm{D}$ employment is $\left(\partial S_{j} / \partial \theta>0\right)$. Indeed, the sum of government expenditure decreases in $\theta$ because $S_{j}>S_{i}$. Therefore, all things being equal, the more innovative firms are dispersed the lower the subsidy to I-firms is.

\subsection{Labor market equilibrium and the growth rate}

\subsubsection{The condition for labor market equilibrium}

As labor is sectorially mobile, it will be used in all three sectors of the economy. The labor supply is fixed and equal to $2 L$. The labor demand in the T-sector is obtained from (5). The quantity of labor used in the M-sector corresponds to the product of the individual production of firms (15), the number of M-firms $\left(N_{w}\right)$ and the marginal need for labor $(\beta)$. The labor demand in the I-sector is simply given by (18). The equilibrium condition on the labor market is:

$$
2 L=\frac{g}{\theta A_{i}+(1-\theta) A_{j}}+L E_{w}\left(\frac{\sigma-\alpha}{\sigma}\right)
$$

As the labor supply is a constant, an equilibrium exists if and only if the labor demand is also a constant. Note that in (20) all terms are constants excepting $E_{w}$. Thus, an equilibrium exists on the labor market if and only if $E_{w}$ is constant over time. This condition is crucial as, according to (7), this implies :

$$
r=\rho
$$

Expression (21) means that the interest rate of riskless assets is constant and equal to the rate of time preference. 


\subsubsection{The equilibrium growth rate}

The equilibrium growth rate is derived from the incentives to innovate. This requires the traditional condition of no arbitrage opportunity between investing in $\mathrm{R} \& \mathrm{D}$ and borrowing at the safe rate $r$. Call $v(t)$ the stock market value of a firm. This value corresponds to the present discounted value of its post tax operating profit. That is,

$$
v(t)=\int_{t}^{\infty} e^{-[R(s)-R(t)]} \frac{\beta x(s)}{\sigma-1}(1-T) d s
$$

where $R(t)=\int_{0}^{t} r(u) d u$ is the cumulative discount factor applicable to profits earned from the period 0 to $t$. Differentiating (22) with respect to time gives us the no arbitrage condition which has to hold at every moment in time in order to ensure stock market equilibrium:

$$
\dot{v}+\frac{\beta x}{\sigma-1}(1-T)=r v
$$

With free entry and zero profits in the I-sector, the value of a firm is equal to the price of one unit of knowledge capital, i.e, the marginal cost of innovation $F$. With $w=1$, this leads to the following equality at the equilibrium:

$$
F=v=\frac{\left(1-S_{i}\right)}{K_{w} A_{i}}
$$

At a steady state, $A_{i}$ and $\left(1-S_{i}\right)$ are constants. We can therefore easily calculate the growth rate of a firm's value:

$$
\frac{\dot{F}}{F}=\frac{\dot{v}}{v}=-g
$$

The firm's value growth rate is equal to the inverse of the growth rate of new varieties. The reason is that an increase in the growth rate means that more firms enter the market. This increases the competition in the M-sector thereby reducing their individual profit. The value of a firm being the present discounted value of its profit, it follows that the value of a firm decreases when growth is positive. Substituting (15), (21), (24), (25) in (23), we can express the no arbitrage condition as:

$$
\frac{\alpha L E_{w} A_{i}(1-T)}{\sigma\left(1-S_{i}\right)}=\rho+g
$$

To obtain the equilibrium growth rate, we have to substitute the expressions (19) and (20) in (26). We have to find the solution of a second degree polynomial function in $g$. There are two solutions but we are most interested in the case where the growth rate is positive, so:

$$
g= \begin{cases}\frac{\Lambda+\sqrt{\Lambda^{2}+8 \alpha \sigma \rho L T\left[\theta A_{i}+(1-\theta) A_{j}\right]}}{2 \sigma} & \text { if } T \in[0,1[ \\ -\rho & \text { otherwise }^{12}\end{cases}
$$




$$
\Lambda=2 L \alpha\left[\theta A_{i}+(1-\theta) A_{j}\right]-\rho(\sigma-\alpha+\alpha T)
$$

\subsubsection{Geography and growth}

It is interesting to study from (27) the relations between the geography of economic activities and aggregate growth. In the related literature [see Martin and Ottaviano (1999), Riou (2003), Baldwin et al.(2003)], only the spatial distribution of M-firms affects the growth rate. Specifically, the spatial concentration of M-firms supports growth because it reduces the cost of innovation for I-firms (due to the spillovers effect). There is no relationship between the location of innovative activities and growth as the entire l-sector is located in the richer region, i.e, region $i$. In our model with a public policy which supports innovation activities and may change the geography of innovation, this leads to the following proposition:

Proposition $1 \mathrm{~A}$ higher concentration of I-firms in the richer region always increases the growth rate (i) whereas a higher concentration of $M$-firms increases growth only if this region hosts the majority of $R \& D$ employment (ii)

\section{Proof 1 (see Appendix A)}

Proposition 1 shows us that the concentration of all economic activities in the larger market supports growth. The positive effect on growth of a higher concentration of the I-sector in the richer region is due to two things. Firstly, the initial productivity ${ }^{13}$ of $R \& D$ is higher in the richer region than in the poorer $\left(A_{i}>A_{j}\right)$ so that with a same number of researchers, region $i$ can produce more innovation than region $j$. Secondly, we know from (19) that the level of subsidies are positively correlated to the concentration of I-firms in the richer region. This means that the subsidy policy will further decrease the cost of innovation if more I-firms are located in this region.

Proposition 1 also shows that the concentration of industrial activities in a region will depend upon the spatial distribution of $R \& D$ employment across regions. More specifically, to have a positive impact upon growth the M-firms need to concentrate in the region where the innovative sector is concentrated. This is due to the fact that the average productivity of I-sector increases (decreases) when the concentration of $\mathrm{M}$-firms increases (decreases) in the region where most of R\&D employment is located. This result shows that the coconcentration of $R \& D$ and production activities in the same location is desirable from the perspective of an aggregate growth rate.

\footnotetext{
${ }^{12}$ When the tax rate is equal to one, the growth rate is negative. The reason being that, if the government taxes all profits, M-firms cannot give a dividend to owners. Therefore, no consumer will invest in M-firms and the no arbitrage condition (26) is satisfied for $g=-\rho$. The government will therefore never fix the tax rate at one.

${ }^{13}$ Before the implementation of the subsidy policy.
} 
We can study a particular case where $R \& D$ employment is dispersed between regions ${ }^{14}$. In this case, the equilibrium growth rate has specific features that we summarize in the following proposition:

Proposition 2 When innovative firms are dispersed, the geography of $M-$ firms does not impact the growth rate (i) and the equilibrium growth rate is lower than that obtained without subsidy policy if $T<T^{*}$ (ii)

\section{Proof 2 (see Appendix A)}

The first result of Proposition 2 is relatively easy to understand. Suppose that $x \%$ of $\mathrm{M}$-firms move from region $j$ to region $i$. Using expressions (20), we can see that this movement of firms will increase the R\&D productivity for I-firms located in region $i$ by $1-\lambda$. By contrast, this will reduce the R\&D productivity for I-firms located in region $j$ by $\lambda-1$. If $\mathrm{R} \& \mathrm{D}$ employment is perfectly distributed between regions, this movement of $M$-firms will not affect the average productivity of $R \& D$ and therefore the incentive to accumulate capital (see (18)). The equilibrium growth rate will remain the same.

The second result shows that, if a public policy disperses innovative activities, the government has to fix his tax rate above a threshold level (noted $T^{*}$ ) to have a positive effect on growth. Under $T^{*}$, the public policy reduces the aggregate growth rate. There are two reasons for this. Firstly, the average productivity of R\&D is lower when I-firms are spread out as opposed to when they are concentrated. Secondly, for a low tax rate level, the tax income is not high enough to equalize the cost of innovation between regions. Thus, the government is obliged to give a negative subsidy (or a tax) to R\&D employment in the richer region to equalize the cost of innovation. The average cost of innovation therefore rises and the growth rate decreases.

\subsection{Income inequality and growth}

To obtain the steady state of the model, we have to define a last equilibrium relation. We have already defined how the equilibrium location of M-firms $\left(s_{n}\right)$ is determined by the expenditure inequality (14) and how the equilibrium growth rate $g$ depends on $s_{n}(27)$. The last relation consists of defining the income and expenditure inequality as a function of $g$. We know that in both regions the nominal expenditure and income of consumers are stable at the steady state. The consumer's income is the sum of his labor income plus his capital income. Concerning the labor income, each worker perceives a salary equal to one at each period. Concerning the capital income, note that in both regions, the capital

\footnotetext{
${ }^{14}$ Remember that the location of R\&D employment corresponds to the location of I-firms to within one constant. Thus, when R\&D employment is symmetric between regions, the richer region hosts the majority of I-firms because in this region, the productivity of $R \& D$ is higher so with an equal quantity of inputs, more innovations appear.
} 
stock of consumers grows at rate $g$ and the value of one unit of capital decreases at rate $g$. Thus, the value of capital income is stable over time. The consumer will then consume his labor income and $\rho$ times the value of the initial per-capita stock of assets as only the profits of this initial stock are pure rents. The income and expenditure of a representative consumer are therefore given by:

$$
E_{i}=1+\frac{\rho K_{i}(0) v(0)}{L} \text { et } E_{j}=1+\frac{\rho K_{j}(0) v(0)}{L}
$$

Using (24), we can rewrite theses expressions as

$$
E_{i}=1+\frac{\rho s_{k}\left(1-S_{i}\right)}{L A_{i}} \text { and } E_{j}=1+\frac{\rho\left(1-s_{k}\right)\left(1-S_{i}\right)}{L A_{i}}
$$

Using expressions (19) and (27) and inserting them into expressions (28), we can express the equilibrium relation between the consumer's share of expenditure $\left(s_{e}\right)$ and the growth rate $(g)$ :

$$
s_{e}=\frac{1}{2}+\frac{\alpha \rho\left(2 s_{k}-1\right)(1-T)}{2 \sigma(g+\rho)}
$$

where $s_{k}=K_{i} / K_{w}$ represents the share of world capital stock owned by region i's consumers. Note that, as long as $s_{k}>1 / 2$ and $T<1$, the nominal income is higher in region $i$ than in region $j$. Moreover, it can noted that the income and expenditure gap decreases in $g$. The reason is that a higher growth rate implies higher competition in the $\mathrm{M}$-sector and therefore a reduction of individual profit. It should be remembered that the value of a firm is the present discounted value of its profits. As income from capital is a more important part of total income in region $i$ than in region $j$, the fall in the firm's value will affect more consumers in region $i$. For this reason, the income inequality between regions decreases with higher growth. This means that if the growth rate decreases, the income inequality rises (cf. Proposition 2).

\subsection{The steady state}

To close the model, we have to define the equilibrium location of M-firms and the growth rate at the steady state. Inserting expressions (27) and (29) into (14), we get the following equilibrium relation:

$$
s_{n}=\frac{1}{2}+\frac{\alpha \rho(1-T)\left(2 s_{k}-1\right)}{\Lambda+\sqrt{\Lambda^{2}+8 L T \alpha \sigma \rho\left[\theta A_{i}+(1-\theta) A_{j}\right]}+2 \sigma \rho}\left(\frac{1+\phi}{1-\phi}\right)
$$

with

$$
A_{i}=s_{n}+\lambda\left(1-s_{n}\right) \quad A_{j}=\lambda s_{n}+\left(1-s_{n}\right)
$$


We can rewrite (30) as $f\left(s_{n}\right): a s_{n}{ }^{3}+b s_{n}{ }^{2}+c s_{n}+d=0$. This implies that $s_{n}$ is the solution of a third degree polynomial function. The solutions of this polynomial function is given in appendix $B$ and depend upon the value of $\theta$. To obtain the equilibrium growth rate, we have to replace the solution of (30) in the expression (27).

\section{Effect of the subsidy policy on the steady state}

In this last section, our objective is to understand the effects of a subsidy policy for innovation on the steady state of the economy. In the related literature [Martin (1999), Riou (2003) and Baldwin et al. (2003)], the common result is that a public policy which increases the geographical scope of spillovers or decreases the cost of innovation will reduce the concentration of $\mathrm{M}$-firms in the richer region, increase the aggregate growth rate and decrease the income inequality. This result is due to the fact that the lower the cost of innovation is, the higher the incentives to accumulate capital and the growth rate are. The relations between $s_{n}$ and $s_{e}(14)$ and between $s_{e}$ and $g(29)$ have the same properties as in our model. Thus, a higher growth rate will reduce the income inequality and the concentration of $\mathrm{M}$-firms in the richer region.

The problem of this result is however that it is obtained by a partial equilibrium analysis. Indeed, none of these models explainsthe origin of the decrease of the innovation cost and how it is financed. In our paper, we investigate whether the result presented in these papers is still valid in a general equilibrium analysis. We will see that this is not always the case.

\subsection{Mechanisms affecting the location of M-firms}

To understand the effects of the subsidy policy on the location of M-firms, we have to analyze the derivative of $s_{n}$ with respect to $T$. For simplicity's sake, in this sub-section, we only highlight the effects coming into play when the subsidy policy is undifferentiated. We can express the impact of an increase of the tax rate on the equilibrium location of M-firms using expressions (14), (27) and (29) as:

$$
\frac{d s_{n}}{d T}=(\underbrace{\frac{\partial s_{n}}{\partial s_{e}} \frac{\partial s_{e}}{\partial g} \frac{\partial g}{\partial T}}_{\text {growth effect }}+\underbrace{\frac{\partial s_{n}}{\partial s_{e}} \frac{\partial s_{e}}{\partial T}}_{\text {income effect }})(\underbrace{1-\frac{\partial s_{n}}{\partial s_{e}} \frac{\partial s_{e}}{\partial g} \frac{\partial g}{\partial s_{n}}}_{\text {productivity effect }})^{-1}
$$

Expression (31) shows that the net effect of the subsidy policy upon the location of M-firms depends on three different channels: 
- The first effect ("growth effect") represents the influence of the subsidy policy upon the location of M-firms via its direct effect on the growth rate. To illustrate this first effect, we suppose that the government raises its tax rate. In this case, the operating profit of M-firms decreases and therefore so does their value $(v)$. Concurrently, the level of subsidies increases and therefore the cost of innovation decreases $(F)$. The Tobin's $q$ method tells us that the equilibrium level of investment in R\&D activities is obtained when $q=v / F=1$, i.e, when the cost of innovation is equal to the value of a firm. Therefore the direct effect of the subsidy policy on the growth rate will depend upon the relative decrease of the cost of innovation, when compared to the decrease of the value of a Mfirm. As demonstrated in appendix $\mathrm{C}$, the direct effect of the subsidy policy on the growth rate is positive, i.e, an increase of the tax rate will cause a greater decrease in the cost of innovation than the value of a M-firm. As the increase of the tax rate raises the growth rate, competition will increase in the M-sector which will lead to a reduction of income inequality (see (29)). The location of M-firms being linked with income inequality (14), a part of M-firms will relocate towards the poorer region to benefit from lower competition. To summarize, the "growth effect" reduces the concentration of M-firms.

-The second effect ("income effect") represents the influence of the subsidy policy on the location of M-firms via its direct effect on income inequality. As before, we illustrate this effect by considering an increase of the tax rate. In this case, the value of an M-firm decreases along with the value of the consumer's assets. As a greater part of the total income of consumers located in region $i$ is related to capital income compared to those located in region $j$, the decrease in the value of M-firms will have a higher impact on the income of region i's consumers. The income inequality between region $i$ and region $j$ will therefore decrease. As before, the decrease of income inequality will lead to a relocation of M-firms towards region $j$. To summarize, the "income effect" reinforces the "growth effect" and pushes a part of the M-firms to move to the poorer region. Consequently, these two effects can be viewed as centrifugal forces.

-The third effect ("productivity effect") represents the influence of the subsidy policy upon the location of M-firms via its indirect effect on R\&D productivity. We have seen that the "growth and income effects" will lead to a reduction of the spatial concentration of M-firms. But as we can see in (27), a decrease in the concentration of M-firms influences the growth rate because it reduces the R\&D productivity (spillovers effect). Thus, the move of M-firms towards the poorer region has in itself an influence upon the growth rate and income inequality. This "productivity effect" will limit the decrease in the spatial concentration of M-firms and forms a centripetal force.

The net effect of the subsidy policy on the location of M-firms depends upon the relative strength of these three effects. It should be noted that the result 
presented by Martin (1999) and Riou (2003) highlights only a part of the "growth effect" and "the productivity effect". As, in these papers, the authors do not consider the issue of funding the public policy, their result is obtained without taking the "income effect" into account nor the fact that the "growth effect" also depends on the financing of the public policy.

After having presented the elements influencing the location of M-firms, we will discuss in the next sub-sections the net effect of the subsidy policy on the equilibrium variables $\left(s_{n}, g, s_{e}\right)$ depending upon the allocation of subsidies between regions.

\subsection{Undifferentiated subsidy policy}

In this section, we consider that the government implements a subsidy policy without trying to influence the geography of innovation. Consequently, in this case, the whole of the l-sector will be located in the richer region to benefit from higher productivity (spillovers effect). In this case we can simplify (27) as:

$$
g= \begin{cases}\frac{\Lambda+\sqrt{\Lambda^{2}+8 \alpha \sigma \rho A L T}}{2 \sigma} & \text { if } T \in[0,1[ \\ -\rho & \text { otherwise }\end{cases}
$$

with

$$
\Lambda=\alpha[2 A L-\rho T]-\rho(\sigma-\alpha)
$$

Using (31), we can easily determine the net effect of the subsidy policy on the location of M-firms. Indeed, the two terms at the numerator are negative and the term at the denominator is positive (see appendix D). We can therefore say that the subsidy policy toward R\&D employment will lead to a more dispersed location equilibrium.

Now, let us consider the derivative of the growth rate with respect to $T$ which is given by

$$
\frac{d g}{d T}=\frac{\partial g}{\partial T}+\frac{\partial g}{\partial s_{n}} \frac{d s_{n}}{d T}
$$

As we can see, the net effect on the growth rate depends upon two effects. As shown in appendix $C$, an increase of the tax rate will increase the incentives to innovate and therefore the equilibrium growth rate $(\partial g / \partial T>0)$. We have however, a second effect related to the movement of $\mathrm{M}$-firms. Indeed, the decrease in the concentration of $\mathrm{M}$-firms will reduce the productivity of $\mathrm{R} \& \mathrm{D}$ activities and finally the growth rate. The net effect on growth will depend upon the relative force of these two effects. We show in appendix $D$ that if

$$
\lambda>\lambda^{*}=\frac{2 L \alpha(L+\rho)+\alpha \rho^{2}(1-T)-L \sigma \rho}{L(2 L \alpha+\sigma \rho)}
$$


then expression (32) is positive, i.e, the net effect of the subsidy policy on the growth rate is positive. Note that (33) represents the strongest possible constraint,i.e, for extreme value of $\phi$ and $s_{n}$. So in most cases the real constraint is less strong than (33). Moreover, considering other constraints (a large amount of demand is devoted to the consumption of the homogeneous good and a positive growth rate) there are a very limited number of cases where the subsidy policy could reduce the growth rate. It could be possible if $\sigma \rightarrow 1$, i.e, if the varieties were not substitutables. But it corresponds to unrealistic growth rates.

Finally, we have to analyze the impact of an increase of the tax rate on the income inequality. The derivative of $s_{e}$ with respect to $T$ is given by:

$$
\frac{d s_{e}}{d T}=\frac{\partial s_{e}}{\partial T}+\frac{\partial s_{e}}{\partial g} \frac{d g}{d T}
$$

As we can see, the net effect of the subsidy policy on the income inequality depends upon two effects. The first is described in the previous sub-section and refers to the fact that a higher tax rate reduces the operating profit of M-firms and the value of the consumer's assets. As consumers in region $i$ have more assets than those in region $j$, income inequality decreases. The second refers to the fact that a higher tax rate increases both the growth rate and competition in the $\mathrm{M}$-sector. This leads to a decrease in profit for M-firms and by using the same mechanism as for the first effect, the income inequality decreases. Consequently, the subsidy policy reduces income inequality. It should also be noted that even for extreme cases where the subsidy policy reduces the growth rate, the net effect on income inequality remains the same (see appendix D).

The analysis of the effects of an undifferentiated subsidy policy on the economy leads to the following proposition :

Proposition 3 A undifferentiated subsidy policy toward R\&D employment reduces industrial agglomeration (i), leads to a higher growth rate (ii) and decreases the income inequality (iii).

\section{Proof 3 (see appendix D)}

In this appendix we also demonstrate that the subsidy policy reduces the Home Market Effect. Proposition 3 confirms the idea that a subsidy policy in favor of innovative activities can reach objectives of both efficiency and equity. As the government does not fix the tax rate at 1 , there will still exist an income inequality between region and a majority of $\mathrm{M}$-firms located in the richer region. In the next sub-section, we will analyze the effect of a geographically differentiated subsidy policy and we will see that the results of proposition 3 do not hold in all circumstances. 


\subsection{Differentiated subsidy policy}

In this sub-section, we will analyze the impact of a geographically differentiated subsidy policy on the steady state. To simplify the analysis, figure 1 summarizes all the effects coming into play and highlights (in dashed gray) the specific effects related to the government's objective of influencing the geography of innovative activities.

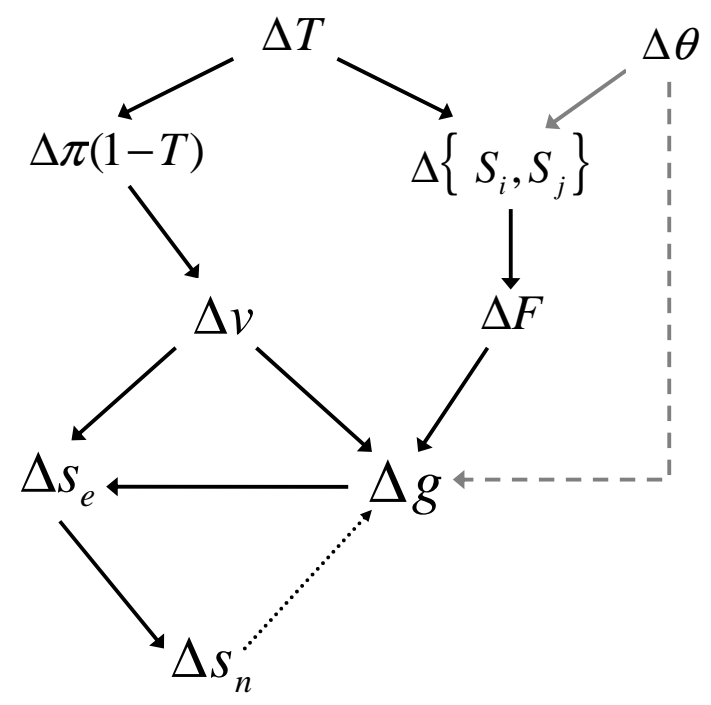

Figure 1 : Channels of influence of a differentiated subsidy policy

For the moment, we only analyze the specific effects highlighted in gray (other effects have already been studied in the previous sub-section). We have so far supposed that the government chooses the proportion of R\&D employment that it will subsidy. As we can see in figure 1, this choice has two different effects.

- The first is that this choice will determine the level of subsidies in each region and therefore the cost of innovation. Indeed to influence the geography of innovative activities, the government has to equalize the cost of innovation between regions. As the initial $R \& D$ productivity is higher in the richer region, the government has to give a higher subsidy to the poorer region to annihilate the surplus of knowledge spillovers that gives them a location in the richer region. A part of the subsidy will therefore be used to fulfill the productivity gap between regions and not to reduce the global cost of innovation. This first effect will reduce the positive effect of the subsidy policy on the cost of innovation and therefore on the incentives to innovate.

- The second effect holds only if the government succeeds in changing the geography of innovation (see discussion §3.2) and directly affects the growth rate. Indeed, if the innovative firms are more spread out, the average productivity of $\mathrm{R} \& \mathrm{D}$ is lower than in the case where the entire l-sector is located in region $i$. 
It is simply because the productivity of $R \& D$ is higher in the region where the majority of $\mathrm{M}$-firms are located, i.e, in region $i$. Therefore this second effect will reduce the growth rate.

To summarize, we can say that the specific effects related to a change of the geography of innovation have a negative impact on the growth rate. A differentiated subsidy policy will therefore always be less efficient than an undifferentiated subsidy policy. Consequently, a trade off between geography and growth reappears. Indeed, if the government policy reduces the spatial concentration of I-firms, this will be at the expense of economic growth $^{15}$.

An other interesting point is to understand whether a differentiated subsidy policy can improve the competitive market outcome, i.e, increases efficiency and equity compared to the situation without intervention of the government. Nevertheless, as a differentiated subsidy policy is more complex to analyze, we cannot conclude analytically and we are obliged to use simulations. Parameter values are based upon those used by Martin and Ottavino (1996) ${ }^{16}$ and the figures presented below compare the steady states obtained without public policy (black points) with those obtained when the government implements an undifferentiated and differentiated subsidy policies. Note that the points in gray represent the threshold level of taxation for which the value of equilibrium variables with a differentiated subsidy equals its value without subsidy policy (black points).

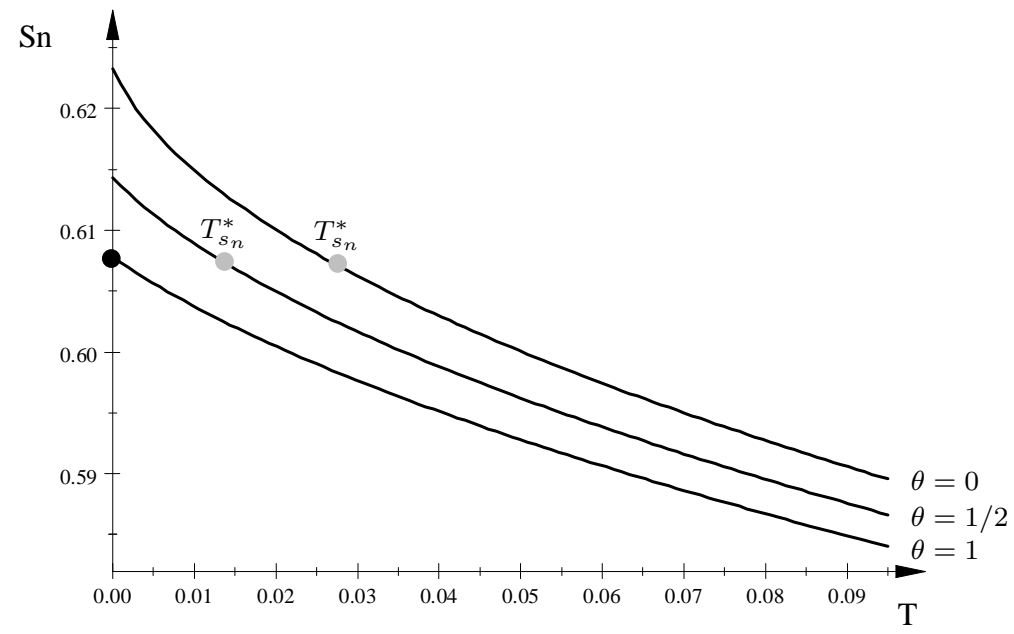

Figure 2: Effect of the subsidy policy on M-firm's location

\footnotetext{
${ }^{15}$ Compared to the case where public policy does not alter the geography of innovation.

${ }^{16}$ Here we use the following parameter values: $\alpha=0.5 ; \rho=0.1 ; \sigma=3 ; \lambda=0.5 ; L=$ $0.4 ; s_{k}=0.7$ and $\phi=0.6$
} 


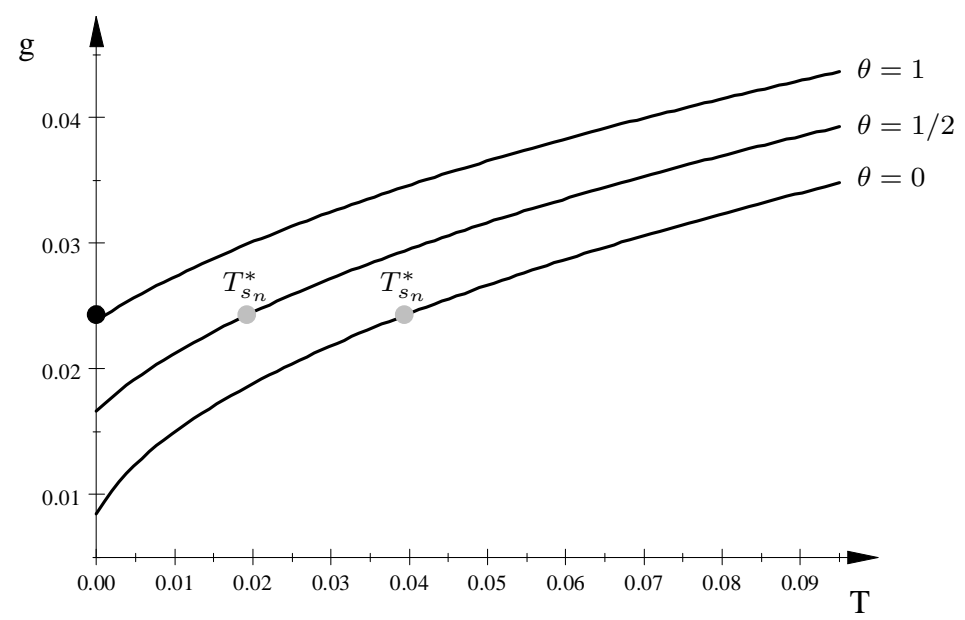

Figure 3: Effect of the subsidy policy on growth

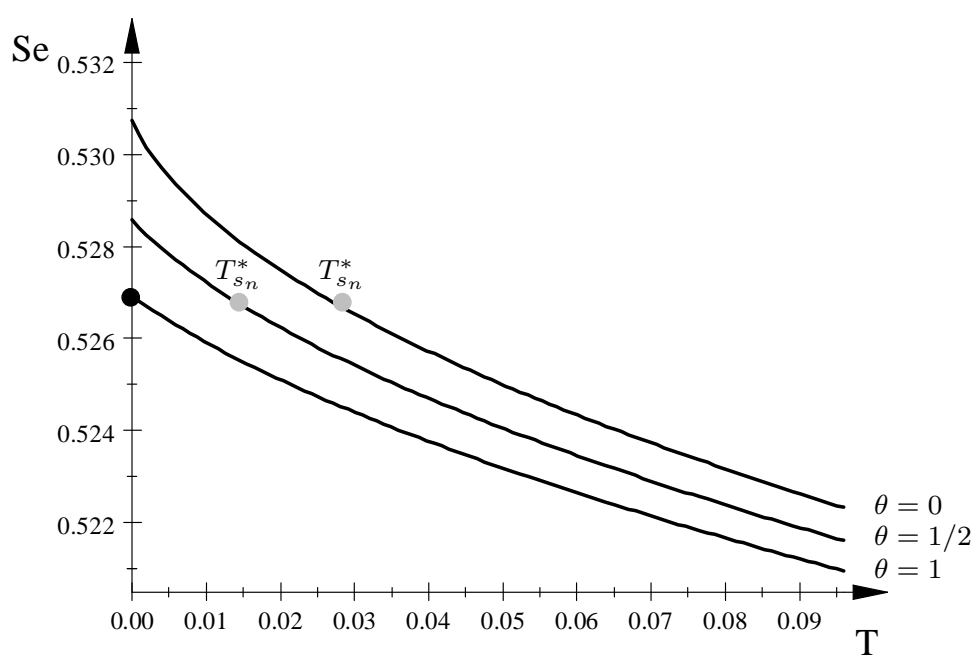

Figure 4: Effect of the subsidy policy on income inequality

Remember that points in light gray $\left(T_{x}^{*}\right)$ represent the threshold level of taxation rate for which the value of equilibrium variable $x$ with a differentiated subsidy equals its value without subsidy policy. As we can see in figures 2-4, an undifferentiated subsidy policy $(\theta=1)$ leads to a more efficient and equitable steady state than the competitive steady state. When the subsidy policy however is geographically differentiated ${ }^{17}$ this is not always the case. Indeed,

\footnotetext{
${ }^{17}$ Here we consider two specific cases, i.e, when the differentiated subsidy policy dispersed the $R \& D$ employment $(\theta=1 / 2)$ or concentrated $R \& D$ employment in the poorer region $(\theta=0)$.
} 
for low levels of tax rate, the differentiated subsidy policy is not efficient and increases inequality between regions. Two effects presented below explain this result. Firstly, for low levels of tax rate, the tax income is insufficient to compensate the productivity gap between regions and it forces the government to fix a negative subsidy to I-firms located in the richer region in order to equalize the cost of innovation between regions. Thus, the cost of innovation rises, the growth rate decreases which increases income inequality and the concentration of $\mathrm{M}$-firms in the richer region. There is also a second effect that reduces the average productivity of $R \& D$. As I-firms are more dispersed, the average productivity of $R \& D$ is lower than in the case where all I-firms are agglomerated in the richer region. This explains why the threshold tax rate at which growth becomes higher than in the case without subsidy policy $\left(T_{g}^{*}\right)$ is higher than the threshold tax rate for the other variables $\left(T_{s_{e}}^{*}=T_{s_{n}}^{*}<T_{g}^{*}\right)$. If the government however fixes the tax rate above $T_{g}^{*}$, the differentiated subsidy policy has positive impact on efficiency and equity. This analysis leads to the following proposition :

Proposition 4 If the subsidy policy is geographically differentiated then the equilibrium outcome is always less efficient and equitable than in the case where the subsidy policy is undifferentiated (i) and than in the case where no public policy is implemented for low level of tax rate (ii)

Proposition 4 shows that there still exists a trade off between efficiency and territorial equity. Martin and Ottaviano (1999), Baldwin et al. (2003), Riou (2003) show in a partial equilibrium analysis that a policy which decreases the cost of innovation increases efficiency and equity. We agree with this result provided that the subsidy policy is undifferentiated. If the subsidy policy is geographically differentiated however the government has to fix the level of tax rate above a threshold level in order to obtain a positive effect on growth and equity.

\section{Conclusion}

In this paper, we propose an extension of the agglomeration and growth model of Martin and Ottaviano (1999). To our knowledge this is the first paper modeling a public sector and analyzing in general equilibrium, the effects of a public policy on this kind of model. Contrary to the related literature that principally analyzes the effect of public policy toward infrastructures, we investigate a subsidy policy toward innovative activities because an increasing amount of public funds in European countries are being used to improve innovation capacity. To be more realistic, we give the government the possibility of geographically differentiating the level of subsidies in order to influence the location of innovative firms. 
A first interesting result of the paper concerns the impact of such a policy upon the relation between geography and growth. Indeed, in the related literature (Martin (1999), Riou (2003), Baldwin et al. (2003)), the concentration of manufacturing firms in the richer country raises the growth rate because of localized knowledge spillovers. We demonstrate that this is true if and only if the majority of innovative activities are also located in the richer region. This shows that growth is fueled by the concentration of all economic activities from design to production. Moreover, this result tells us that a configuration with a region specialized in production activities and the other in design activities is not optimal in terms of growth. We also highlight an interesting result that concerns the particular case where R\&D employment is dispersed between regions. Indeed, we show that, the geography of manufacturing firms does not influence the equilibrium growth rate as in the case where knowledge spillovers are supposed global.

A second interesting result concerns the effect of such a policy on the economy. We show that the public subsidy towards innovative firms can reach the objectives of both higher growth and equity as demonstrate by Martin (1999) and Riou (2003) if the subsidies are undifferentiated. But we can reasonably think that the government may have other objectives than increasing innovation dynamics as a whole, such as changing the spatial distribution of innovative firms between regions. We show that when public support for innovation reduces the concentration of I-firms, the positive impact of the public policy is weaker. Moreover, when public policy is insufficient (i.e low tax rate) then the impact on growth and equity is negative. In other words, to reach the objectives of both higher growth and equity, public authorities would have two options: either subsidizing innovative firms without trying to influence their choice of location or influencing their choice of location with geographically differentiated subsidies. In this case, however, the resources devoted to this policy would have to be (much) higher.

So, if we linked these theoretical results to the context of the New European Regional Policy (2007-2013), it appears that the shift in the strategy of allocation of funds in the Lisbon objectives is heading in the right direction to reach the objectives of both higher growth and equity between European regions. The fact however, that European Regional Policy represents a very little part of total public expenditure in Europe and that it is clearly oriented towards poorer regions are elements that could make the policy inefficient.

In this paper, we suppose that public policy is implemented by a central government which taxes both regions identically. A natural extension of our analysis would be to suppose that the policy is implemented at a regional level by two different public authorities that are in competition. Another possible extension would be to study the implications of the public policy in terms of welfare according to various criteria as Bentham, Pareto or Rawls. This will be 
the object of future research.

\section{Acknowledgements}

I wish to thank Nadine Massard and Stephane Riou for providing numerous suggestions that have substantially improved the article. I have also benefited from comments of participants at the $4^{\text {th }}$ UMR SMART INRIA conference on "Economics and Space" in Rennes and I specially thank Jacques-François Thisse, Kristian Behrens, Carl Gaigné, Nelly Exbrayat and Fabien Candau.

\section{Appendix}

\section{Appendix A}

In this appendix, we demonstrate the results of propositions 1 and 2 .

\section{Proof of Proposition 1}

Remember that the equilibrium growth rate of our economy is given by (27). To understand the effect of an increase of the spatial concentration of M-firms on the growth rate, we calculate the first derivative of $g$ with respect to $s_{n}$. This first derivative is given by:

$$
\frac{\partial g}{\partial s_{n}}=\frac{\alpha L(1-\lambda)(2 \theta-1)}{\sigma}\left(1+\frac{\Lambda+2 T \sigma \rho}{\sqrt{\Lambda^{2}+8 \alpha \sigma \rho L T\left[\theta A_{i}+(1-\theta) A_{j}\right]}}\right)
$$

with

$$
\Lambda=2 L \alpha\left[\theta A_{i}+(1-\theta) A_{j}\right]-\rho(\sigma-\alpha+\alpha T)
$$

so, we have:

$$
\frac{\partial g}{\partial s_{n}} \lesseqgtr 0 \quad \text { if } \theta \lesseqgtr \frac{1}{2}
$$

An increase of the concentration of $\mathrm{M}$-firms in the richer region increases the growth rate if and only if the majority of I-firms is located in this region.

In the same vein, we can easily demonstrate that an increase of the concentration of innovative activities in the richer region increases the equilibrium growth rate by calculating the first derivative of $g$ with respect to $\theta$ :

$$
\frac{\partial g}{\partial \theta}=\frac{2 L \alpha\left(A_{i}-A_{j}\right)(g+T \rho)}{\sqrt{\Lambda^{2}+8 \alpha \sigma \rho L T\left[\theta A_{i}+(1-\theta) A_{j}\right]}}>0
$$




\section{Proof of Proposition 2}

Here, we demonstrate the results of proposition 2. Specifically, we show that for the particular case where R\&D employment is spread out over regions, the geography of industrial firms (M-firms) has no impact upon the growth rate as in the case where spillovers are not localized. Moreover, we can prove that below a certain level of tax rate, the equilibrium growth rate is lower than in the case where public policy is not implemented. When R\&D employment is dispersed, the average productivity of R\&D does not depend on the geography of I-firms and is given by $(1 / 2)(1+\lambda)$. Therefore the equilibrium growth rate is given by (27) becomes:

$$
g=\frac{\Psi+\sqrt{\Psi^{2}+4 L T \alpha \sigma \rho(1+\lambda)}}{2 \sigma}
$$

with

$$
\Psi=L \alpha(1+\lambda)-\rho(\sigma-\alpha+T \alpha)
$$

Now, we want to demonstrate that there exists a threshold tax rate below which this equilibrium growth rate is lower than that obtained without subsidy policy. To do this we have to calculate the growth rate of the economy when no public policy is implemented, i.e, the case studied by Martin and Ottaviano (1999)

$$
g=\frac{2 L \alpha A_{i}-\rho(\sigma-\alpha)}{\sigma}
$$

where $A_{i}$ is the same as in our definition, see (16). The equilibrium location of $\mathrm{M}$-firms is given by the following expression

$$
s_{n}=\frac{(1-\phi)(L-\rho-3 L \lambda)+\sqrt{A+B+C}}{4 L(1-\phi)(1-\lambda)}
$$

with

$$
\begin{gathered}
\left.A=\left[L^{2}(1+\lambda)^{2}+\rho^{2}\right)(1-\phi)^{2}\right] \\
B=8 L s_{k}(1-\lambda)\left(1-\phi^{2}\right) \\
C=2 L \rho(1-\phi)(3 \lambda-3 \phi+\lambda \phi-1)
\end{gathered}
$$

We want to define the threshold tax rate below which the growth rate of the economy without public policy is higher than with public policy and a dispersion of $R \& D$ employment and we obtain:

$$
\begin{gathered}
T^{*}=\frac{2 L \alpha\left(2 s_{k}-1\right)(1+\phi)(1-\lambda)+\sigma D-\sigma \sqrt{A+B+C}}{(2 \sigma-\alpha) D-\alpha \sqrt{A+B+C}} \\
D=(1-\phi)(L(1+\lambda)+\rho)
\end{gathered}
$$


If the tax rate is lower than $T^{*}$, the equilibrium growth rate of the economy with public subsidy (and a dispersed geography of $R \& D$ employment) is lower than without public intervention.

\section{Appendix B}

The equilibrium location of M-firms has to satisfy the condition given by (30). We can rewrite (30) as a third degree polynomial function of $s_{n}: f\left(s_{n}\right)$ : $a s_{n}{ }^{3}+b s_{n}{ }^{2}+c s_{n}+d=0$ with

$$
\begin{gathered}
a=-8 L \alpha \sigma \rho(1-\lambda)(2 \theta-1)(1-T) \\
b=\frac{2 \psi[\varphi-\eta]}{1-\phi}
\end{gathered}
$$

$\psi=2 \alpha \rho(1-T)$

$\varphi=L \alpha(2 \theta-1)\left(2 s_{k}-1\right)(1-\lambda)(1+\phi)$

$\eta=\sigma(1-\phi)(4 L+\rho-6 L \theta(1-\lambda)-2 L \lambda)$

$$
c=\psi(A-B-C-D)
$$

$A=\left[\alpha(1+\phi)\left(4 L \theta(1-\lambda)-3 L-2 L \lambda s_{k}\right)\right]$

$B=\left(\frac{1+\phi}{1-\phi}\right)\left(2 s_{k}-1\right)[4 L \theta \alpha \phi(1-\lambda)-\phi \rho(\alpha+\sigma)+T \alpha \rho-L \alpha \phi(3-\lambda)]$

$C=\left[(6 L \theta+L \lambda-\rho)(\sigma-\alpha)-\rho(\sigma+\alpha)\left(2 s_{k}(1+\phi)-\phi\right)\right]$

$D=\left[8(1-\lambda) L s_{k} \theta \alpha(1+\phi)-L\left(5 \sigma+\alpha \lambda \phi-6\left(\alpha \theta-\theta \sigma \lambda-\alpha s_{k}-\alpha s_{k} \phi\right)\right]\right.$

$$
d=-\frac{\psi}{2}(E+F)+G(H+I)
$$

$E=\left[2 L(1-\theta+\theta \lambda)\left(\sigma+\alpha(1+\phi)\left(2 s_{k}-1\right)\right)-2 s_{k} \alpha \rho(1-T)(1+\phi(2 \phi+3))\right]$

$F=\left[\rho(1+\phi)\left(2 k \sigma+\alpha(1-T)\left(4 s_{k}^{2}(1+\phi)+\phi\right)\right)-\sigma \phi \rho\right]$

$G=-\alpha \phi \rho\left(2 s_{k}-1\right)(1+\phi)(1-T)$

$H=\left[2 L \alpha(1-\phi)(1-\theta(1-\lambda))+2 \alpha \rho(1-T)\left(2 s_{k}-\phi+s_{k} \phi(1-\phi)\right)\right](1-\phi)^{-2}$

$I=\left[-\rho(1-\phi)(\alpha(1+\phi)-\sigma)+T \alpha \rho\left(1-\phi^{2}\right)\right](1-\phi)^{-2}$

There are three real solutions to such an equation but by using expression (30) and simulations, we can easily see that only one is available depending upon the value of $\theta$. The solution of (30) is given by:

$$
\begin{aligned}
& s_{n}=2 \sqrt{-\frac{p}{3}} \cos \left(\frac{\arccos \left(\frac{3 q}{2 p} \sqrt{-\frac{3}{p}}\right)+4 \pi}{3}\right)-\frac{b}{3 a} \text { if } \theta>\frac{1}{2} \\
& s_{n}=2 \sqrt{-\frac{p}{3}} \cos \left(\frac{\arccos \left(\frac{3 q}{2 p} \sqrt{-\frac{3}{p}}\right)+2 \pi}{3}\right)-\frac{b}{3 a} \text { if } \theta<\frac{1}{2}
\end{aligned}
$$


with

$$
\begin{gathered}
p=\frac{c}{a}-\frac{b^{2}}{3 a^{2}} \\
q=\frac{d}{a}+\frac{b}{27 a}\left(\frac{2 b^{2}}{a^{2}}-\frac{9 c}{a}\right)
\end{gathered}
$$

Note that when $T=0$, the concentration of $\mathrm{M}$-firms in the richer region is complete $\left(s_{n}=1\right)$ when the degree of trade integration exceeds the threshold level:

$$
\phi^{*}=\frac{L+\rho(1-k)}{L+\rho k}
$$

\section{Appendix C}

This appendix provides a formal demonstration of why an increase in the tax rate increases the incentives to accumulate capital. For this, we use the Tobin's $q(1969)$ which is defined by the ratio $v / F$ where $v$ is the value of a firm and $F$ is its cost. Using the labor market equilibrium condition given by (20), we can write:

$$
L E_{w}=\left(2 L-\frac{g}{\left[\theta A_{i}+(1-\theta) A_{j}\right]}\right)\left(\frac{\sigma}{\sigma-\alpha}\right)
$$

Using (23) and replacing the previous expression, we obtain:

$$
v=\frac{\pi(1-T)}{\rho+g}=\frac{\alpha\left(2 L-\frac{g}{\left[\theta A_{i}+(1-\theta) A_{j}\right]}\right)\left(\frac{\sigma}{\sigma-\alpha}\right)(1-T)}{\sigma N_{w}(\rho+g)}
$$

Using (17), (19) and (20), we can rewrite the equilibrium subsidy to I-firms located in the poorer region as:

$$
S_{j}=\frac{g \theta(\sigma-\alpha)\left(A_{i}-A_{j}\right)+2 L T \alpha A_{j}\left[\theta A_{i}+(1-\theta) A_{j}\right]-T g \alpha A_{j}}{g(\sigma-\alpha)\left[\theta A_{i}+(1-\theta) A_{j}\right]}
$$

Using this expression and replacing it in the expression of the cost of innovation leads to the following expression:

$$
F_{I}^{j}=F_{I}^{i}=\frac{g(\sigma-\alpha+T \alpha)-2 L T \alpha\left[\theta A_{i}+(1-\theta) A_{j}\right]}{N_{w} g(\sigma-\alpha)\left[\theta A_{i}+(1-\theta) A_{j}\right]}
$$

To understand the direct influence of the tax rate upon the incentives to innovate (without taking the effect of $T$ on the geography of $\mathrm{M}$-firms into account), we will compare the first derivative of $v$ and $F_{I}$ with respect to $T$.

$$
\frac{\partial v}{\partial T}=-\frac{\alpha}{(g+\rho) N_{w}} \frac{2 L\left[\theta A_{i}+(1-\theta) A_{j}\right]-g}{(\sigma-\alpha)\left[\theta A_{i}+(1-\theta) A_{j}\right]}
$$




$$
\frac{\partial F}{\partial T}=-\frac{\alpha}{g N_{w}} \frac{2 L\left[\theta A_{i}+(1-\theta) A_{j}\right]-g}{(\sigma-\alpha)\left[\theta A_{i}+(1-\theta) A_{j}\right]}
$$

Note that the only difference between these two first derivatives is the presence of the time preference parameter $\rho$ at the denominator of $\partial v / \partial T$. This result demonstrates that the effect of an increase of the tax rate is higher for the cost of innovation $(F)$ than for the value of a firm $(v)$ because the cost of innovation is not subject to a subjective discount factor contrary to the profit of $\mathrm{M}$-firms. The fact that $\partial F / \partial T>\partial v / \partial T$ explains why an increase of the tax rate increases both the incentives to accumulate as well as the equilibrium growth rate.

\section{Appendix D}

\section{Proof of Proposition 3}

\section{Sign of the derivative of $s_{n}$ with respect to $T$}

Consider the case where the subsidy policy is undifferentiated and then the derivative of $s_{n}$ with respect to $T$ is given by:

$$
\frac{d s_{n}}{d T}=\left(\frac{\partial s_{n}}{\partial s_{e}} \frac{\partial s_{e}}{\partial g} \frac{\partial g}{\partial T}+\frac{\partial s_{n}}{\partial s_{e}} \frac{\partial s_{e}}{\partial T}\right)\left(1-\frac{\partial s_{n}}{\partial s_{e}} \frac{\partial s_{e}}{\partial g} \frac{\partial g}{\partial s_{n}}\right)^{-1}
$$

Using expression (14), (27) and (29) we have:

$$
\begin{gathered}
\frac{\partial s_{n}}{\partial s_{e}}=\frac{1+\phi}{1-\phi}>0 \quad \frac{\partial s_{e}}{\partial g}=-\frac{\alpha \rho\left(2 s_{k}-1\right)(1-T)}{2 \sigma(g+\rho)^{2}}<0 \\
\frac{\partial g}{\partial T}=\frac{\alpha \rho}{2 \sigma}\left(\frac{4 A_{i} L \sigma-g}{\sqrt{\Lambda^{2}+8 A_{i} L T \alpha \sigma \rho}}\right)>0 \quad \frac{\partial s_{e}}{\partial T}=-\frac{\alpha \rho\left(2 s_{k}-1\right)}{2 \sigma(g+\rho)}<0 \\
\frac{\partial g}{\partial s_{n}}=\frac{L \alpha(1-\lambda)}{\sigma}\left(\frac{g+2 T \sigma \rho}{\sqrt{\Lambda^{2}+8 A_{i} L T \alpha \sigma \rho}}\right)>0
\end{gathered}
$$

with

$$
\Lambda=\alpha\left[2 A_{i} L-\rho T\right]-\rho(\sigma-\alpha)
$$

Using signs of these partial derivatives, we see immediately that an increase of the tax rate will reduce the spatial concentration of $\mathrm{M}$-firms in the richer region, i.e, $d s_{n} / d T<0$. 


\section{Sign of the derivative of $g$ with respect to $T$}

Consider now the derivatives of the growth rate (27) and the income inequality (29) with respect to $T$. These are given by:

$$
\begin{aligned}
& \frac{d g}{d T}=\frac{\partial g}{\partial T}+\frac{\partial g}{\partial s_{n}} \frac{d s_{n}}{d T} \\
& \frac{d s_{e}}{d T}=\frac{\partial s_{e}}{\partial T}+\frac{\partial s_{e}}{\partial g} \frac{d g}{d T}
\end{aligned}
$$

Inserting (38) in (37), we can rewrite (37) as:

$$
\frac{d g}{d T}=\left(\frac{\partial g}{\partial T}+\frac{\partial g}{\partial s_{n}} \frac{\partial s_{n}}{\partial s_{e}} \frac{\partial s_{e}}{\partial T}\right)\left(1-\frac{\partial s_{n}}{\partial s_{e}} \frac{\partial s_{e}}{\partial g} \frac{\partial g}{\partial s_{n}}\right)^{-1}
$$

Using signs of the partial derivatives, we know that the second term of this expression is positive so the sign of $d g / d T$ depends upon the sign of the first term. Using expressions of partial derivatives, we obtain:

$$
\left(\frac{\partial g}{\partial T}+\frac{\partial g}{\partial s_{n}} \frac{\partial s_{n}}{\partial s_{e}} \frac{\partial s_{e}}{\partial T}\right)=A B
$$

with

$$
\begin{gathered}
A=\frac{\alpha \rho}{\sigma(1-\phi)(g+\rho)} \\
B=\frac{\sigma(1-\phi)(g+\rho)\left(2 A_{i} L-g\right)-L \alpha(1+\phi)(1-\lambda)\left(2 s_{k}-1\right)(g+T \rho)}{\sqrt{\Lambda^{2}+8 A_{i} L T \alpha \sigma \rho}}
\end{gathered}
$$

$A$ is positive and the denominator of $B$ is also positive so we know that $\operatorname{sign}(d g / d t)=\operatorname{sign}(B)$. Note that without subsidy policy, all M-firms are concentrated in the richer region when $\phi \geq \phi^{*}$ (see the end of appendix C). So, replacing $\phi$ by $\phi^{*}$, we obtain:

$$
\frac{d g}{d T}>0 \text { if } \frac{\sigma(g+\rho) \rho\left(2 A_{i} L-g\right)}{L \alpha(1-\lambda)(2 L+\rho)(g+T \rho)}>1
$$

Solving this second degree inequality in $g$, we obtain:

$$
\frac{d g}{d T}>0 \text { if } g<g^{*}=\frac{\Upsilon+\sqrt{\Upsilon^{2}+4 L \sigma \rho^{2}\left[2 A_{i} \sigma \rho-T \alpha(1-\lambda)(2 L+\rho)\right]}}{2 \sigma \rho}
$$

with

$$
\Upsilon=\sigma \rho\left(2 A_{i} L-\rho\right)-L \alpha(1-\lambda)(2 L+\rho)
$$

Note that if we prove that $\rho \Lambda<\Upsilon$ then $g<g^{*}$. Indeed, the condition $\rho \Lambda<\Upsilon$ is more restrictive than $g<g^{*}$ and corresponds to:

$$
\rho \alpha\left[2 A_{i} L-\rho T\right]-\rho^{2}(\sigma-\alpha)<\sigma \rho\left(2 A_{i} L-\rho\right)-L \alpha(1-\lambda)(2 L+\rho)
$$


which is equivalent to

$$
s_{n}>s_{n}^{*}=\frac{1}{2}-\frac{L \sigma \rho(1+\lambda)-2 L \alpha[L(1-\lambda)+\rho]-\alpha \rho^{2}(1-T)}{2 L \rho(1-\lambda)(\sigma-\alpha)}
$$

We are sure that $s_{n}>s_{n}^{*}$ if $L \sigma \rho(1+\lambda)-2 L \alpha[L(1-\lambda)+\rho]-\alpha \rho^{2}(1-T)>0$. This condition is satisfied when

$$
\lambda>\lambda^{*}=\frac{2 L \alpha(L+\rho)+\alpha \rho^{2}(1-T)-L \sigma \rho}{L(2 L \alpha+\sigma \rho)}
$$

If this condition for $\lambda$ is verified, then an increase of the tax rate will increase the aggregate growth rate. Note that this condition is the strongest possible constraint, i.e, for the extreme value of $\phi$ and $s_{n}$. So in most cases the constraint is weaker than (33).

\section{Sign of the derivative of $s_{e}$ with respect to $T$}

The sign of $d s_{e} / d T$ is more easily determined than for $d g / d T$. We could work with (38) to determine the sign of $d s_{e} / d T$ but this is easily done by considering the following expression:

$$
\frac{d g}{d T}=\left(\frac{\partial g}{\partial T}+\frac{\partial g}{\partial s_{n}} \frac{\partial s_{n}}{\partial s_{e}} \frac{\partial s_{e}}{\partial T}\right)\left(1-\frac{\partial s_{n}}{\partial s_{e}} \frac{\partial s_{e}}{\partial g} \frac{\partial g}{\partial s_{n}}\right)^{-1}
$$

Inserting expression (38) in this expression, we get

$$
\frac{d g}{d T}=\frac{\partial g}{\partial T}+\frac{\partial g}{\partial s_{n}} \frac{\partial s_{n}}{\partial s_{e}} \frac{d s_{e}}{d T}
$$

If we compare this expression with (37), we can see that the following equality holds:

$$
\frac{d s_{n}}{d T}=\frac{\partial s_{n}}{\partial s_{e}} \frac{d s_{e}}{d T}
$$

As $\partial s_{n} / \partial s_{e}>0$ and $d s_{n} / d T<0$, we know that $d s_{e} / d T<0$, i.e, an increase of the tax rate will lead to a decrease of the income inequality between regions. This proves that even if we consider extreme cases where $\lambda<\lambda^{*}$, i.e, even if an increase of the tax rate reduces the growth rate, it reduces the income inequality. Therefore, for realistic cases where the subsidy policy increases the growth rate, the decrease of income inequality is stronger.

We can also determine the effect of an increase of the tax rate on the Home Market Effect. Indeed, expression (39) shows that the higher the tax rate is, the lower the Home Market Effect is. The reason is simply that $\partial s_{n} / \partial s_{e}>1$, so an increase of the tax rate will decrease the concentration of M-firms even more than the income inequality. 


\section{References}

[1] Baldwin R. \& Martin P. (2004), "Agglomeration and Regional Growth", in Vernon Henderson J. \& Thisse J-F., Handbook of Regional and Urban Economics, vol.4 Cities and Geography, chap. 60, p. 2670-2711

[2] Baldwin R., Forslid R., Martin P., Ottaviano G. \& Robert-Nicoud F. (2003), "Economic Geography and Public Policy", Princeton University Press

[3] Baldwin R., Martin P. \& Ottaviano G. (2001), "Global Income Divergence, Trade, and Industrialization: The Geography of Growth Take-Offs", Journal of Economic Growth, vol.6, p. 5-37

[4] Baldwin R. \& Forslid R. (2000a), "Trade liberalisation and endogenous growth: A q-theory approach", Journal of International Economics, vol.50, p.497-517

[5] Baldwin R. \& Forslid R. (2000b), "The Core-Periphery model and endogenous growth: stabilizing and de-stabilizing integration", Economica, ${ }^{\circ} 67$, pp. 307-324

[6] Barro R. \& Sala-I-Martin X. (1996), "La croissance économique", Ediscience / McGraw-Hill, Collection sciences Economiques

[7] Becker J. \& Fuest C. (2010), "EU regional policy and tax competition", European Economic Review, n ${ }^{\circ} 2$, p.150-161

[8] Combes P-P, Mayer T. \& Thisse J-F. (2006), "Economie Géographique: $L$ 'intégration des régions et des nations", Economica

[9] Englmann F.C. \& U. Walz (1995), "Industrial centers and regional growth in the presence of local inputs", Journal of Regional Science, n ${ }^{\circ} 35$, pp. 3-27

[10] Fujita M. \& Thisse J-F. (2002), "On the Relationship between Agglomeration and Growth", in Fujita M. \& Thisse J-F., Economics of agglomeration: cities, industrial location and regional growth, Cambridge University Press, p.388-452

[11] Grossman G. \& Helpman E. (1991), "Innovation and Growth in the Global Economy", MIT Press, Cambridge CA

[12] Heraud J-A, Ouardighi J. \& Kahn R. (2004), "Une relecture de la politique régionale européenne et du rôle des collectivités: l'exemple des politiques 
de recherche et d'innovation", 10ème colloque de l'ASRDLF "Convergence et disparités régionales au sein de l'espace européen : les politiques régionales à l'épreuve des faits", Bruxelles 1-3 septembre 2004

[13] Krugman P. (1991), "Increasing Returns and Economic Geography", Journal of Political Economy, n ${ }^{\circ}$ 99, p.483-499

[14] Lejour A.M. \& Verbon H. (1997), "Tax Competition and Redistribution in a Two-Country Endogenous-Growth model", International Tax and Public Finance, vol. 4, p.485-497

[15] Martin P. \& Ottaviano G. (1996), "Growth and Agglomeration", Document de travail $n^{\circ} 96-14$, CEPII

[16] Martin P. (1998), "Can Regional Policies Affect Growth and Geography in Europe?", The World Economy, n²1, vol.6, p.757-774

[17] Martin P. \& Ottaviano G. (1999), "Growing locations: Industry Location in a Model of Endogenous Growth", European Economic Review n ${ }^{\circ} 43$, p. $281-$ 302

[18] Martin P. (1999), "Public policies, regional inequalities and growth", Journal of Public Economics n` 73 , p.85-105

[19] Martin P. \& Ottaviano G. (2001), "Growth and Agglomeration", International Economic Review, vol. 42 (4), pp. 947-968

[20] Martin P. \& Dupont V. (2006), "Subsidies to poor regions and inequalities: some unpleasant arithmetic", Journal of Economic Geography, vol.2, p. 223-240

[21] Minniti A. \& Parello C.P (2010), "Trade integration and regional disparity in a model of scale-invariant growth", Regional Science and Urban Economics, forthcoming

[22] Riou S. (2003), "How growth and location are sensitive to transport and telecommunications infrastructures", Recherches Economiques de Louvain, vol. 69 , p. $241-265$

[23] Riou S. (2003), "Géographie, croissance et politique de cohésion en Europe", Revue française d'Economie, vol.17, p.171-220

[24] Romer P. (1990), "Endogenous Technologocal Change", The Journal of Political Economy, vol. 98, n`5, p.71-102 
[25] Rogers C. \& Martin P. (1995), "Industrial location and pulic infrastructure", Journal of International Economics, n³9, p. 333-351

[26] Walz U. (1999), "Dynamics of Regional Integration", Physica-Verlag Edition, New York

[27] Walz U. (1996), "Transport costs, intermediate goods and localized growth", Regional Science and Urban Economics, n²6, pp.671-695 